REVISTA DE GESTÃO ESECRETARIADO

MANAGEMENT AND ADMINISTRATIVE

PROFESSIONAL REVIEW

ISSN: 2178-9010
Revista GeSec

São Paulo, SP, Brasil

v. 12 , n. 2, p. $94-121$

maio /ago. 2021

DOI: http://dx.doi.org/10.7769/gesec.v12i2.1123

\title{
Gerenciando o conflito trabalho-família no empreendedorismo feminino: evidências de um estudo com microempreendedoras individuais
}

\section{Managing the work-family conflict in female entrepreneurship: evidence from a study with individual microentrepreneurs}

\author{
Hávila Maria Abreu Barbosa ${ }^{1}$ \\ Manoel Pereira da Rocha Neto ${ }^{2}$ \\ Sueldo Lopes Câmara Júnior ${ }^{3}$ \\ Pablo Marlon Medeiros da Silva ${ }^{4}$
}

\section{Resumo}

O presente artigo teve como objetivo compreender como o conflito trabalho-família impacta o empreendedorismo feminino e as estratégias adotadas para o seu equilíbrio. O estudo apresentou natureza descritiva, com abordagem qualitativa, com metodologia baseada na fenomenologia, e com recurso à realização de 10 entrevistas aprofundadas com mulheres microempreendedoras do ramo de confeitaria da cidade de Natal/RN. Os resultados mostraram que há conflito nos diferentes domínios para todas as entrevistadas. Constatou-se que houve, na maioria dos casos, o apoio familiar e do cônjuge para a continuidade dos negócios, mas ainda perduram sentimentos de indiferença, incompreensibilidade e não aceitação ao empreendimento. Percebeu-se também que a maior parte dos deveres domésticos é da mulher, fator que gera uma maior sobrecarga em seus diferentes papéis, especialmente para aqueles que possuem filhos. Fatores como tempo e o exercício das atividades profissionais dentro da própria casa foram evidenciados como sendo elementos potenciais para acentuar os conflitos. Dentre as principais estratégias mencionadas para minimizar os conflitos estão o compartilhamento de

\footnotetext{
${ }^{1}$ Mestre em Administração, Administradora no Instituto Federal de Educação, Ciência e Tecnologia do Rio Grande do Norte (IFRN).

${ }^{2}$ Doutor em Educação, Docente no Centro Universitário Doutor Leão Sampaio (UNILEÃO)

${ }^{3}$ Mestre em Administração, Administrador no IFRN.

${ }^{4}$ Doutor em Administração, Docente na Universidade Federal Rural do Semi-Árido (UFERSA).
} 
papéis, seja para familiares ou para terceiros. O estudo traz importantes contribuições para um campo ainda pouco investigado quando se trata de trabalho e família.

Palavras-chave: Mulheres. Empreendedorismo. Conflito. Trabalho. Família.

\begin{abstract}
This article aimed to understand how the work-family conflict impacts female entrepreneurship and the strategies adopted for its balance. The study was descriptive in nature, with a qualitative approach, using a phenomenological research tradition. Following this research tradition, we undertook 10 in depth interviews with women micro entrepreneurs in the confectionery industry in Natal / RN. The results showed that there was conflict in the different domains for all interviewees. It was found that, in most cases, there was family and spouse support for business continuity, but feelings of indifference, incomprehensibility and non-acceptance of the enterprise still persist. It was also noticed that most of the domestic duties are women, a factor that creates a greater burden in their different roles, especially for those who have children. Factors such as time and the exercise of professional activities within the home were shown to be potential elements to accentuate conflicts. Among the main strategies mentioned to minimize conflicts are the sharing of roles, either for family members or for third parties. The study brings important contributions to a field that is still little investigated when it comes to work and family.
\end{abstract}

Keywords: Women. Entrepreneurship. Conflict. Job. Family.

\title{
Introdução
}

A participação feminina tem ganhado importante destaque quando se fala em empreendedorismo (Cisneros, 2015). Enquanto no Brasil as mulheres têm se igualado aos homens em número de empreendimentos, ao analisar a taxa de empreendedorismo inicial feminino, constata-se que o Brasil (19,9\%) fica à frente de países como Estados Unidos (10,5\%), China (8,6\%) e Alemanha (3,1\%) (Global Entrepreneurship Monitor, 2017). Ressaltase ainda que $47 \%$ dos microempreendedores individuais (MEI) e 39\% dos micros e pequenos empresários são mulheres (CNDL; SPC Brasil, 2015) e que a fabricação de alimentos, comércio de artigo de vestuários, serviços de buffet e atividades ligadas a beleza são os segmentos com maior participação de mulheres empreendedoras (Global Entrepreneurship Monitor, 2017).

Assim, motivadas pela percepção de oportunidades ou impulsionadas pelas necessidades, as mulheres empreendedoras têm sido relevantes para o empreendedorismo. 
Entretanto, o contexto atual que envolve os negócios leva o público feminino a enfrentar circunstâncias altamente voláteis que as conduzem a uma série de estressores que podem afetar sua vida profissional e familiar (Nambisan \& Baron, 2019; Teoh, Chong, Chong, \& Ismail, 2016). Como consequência, o problema em conciliar as atividades do empreendimento com questões familiares pode ser uma barreira para os seus objetivos de sucesso (Silva, El-Aouar, Silva, Castro \& Sousa, 2019), pelas tensões provenientes de elementos como sobrecarga, ambiguidade e diversidade de papéis vivenciados (Nambisan \& Baron, 2019). Esse contexto leva à seguinte questão de pesquisa: como o conflito trabalho-família pode impactar o empreendedorismo feminino?

Assim, este artigo tem como objetivo compreender o impacto do conflito trabalhofamília no empreendedorismo feminino e as estratégias adotadas para o seu equilíbrio. Para isso, foram escolhidas 10 microempreendedoras individuais do ramo de confeitaria de uma capital nordestina. Adicionalmente, a teoria da fronteira, proposta por Clark (2000), foi utilizada como lente teórica, visando comparar as práticas realizadas pelas entrevistadas nos diferentes domínios com as teoricamente propostas, a fim de analisar suas nuances no fenômeno ora investigado. A importância do tema se dá por o conflito trabalho-família ter ganhado relevância científica e social, pois tem importantes consequências para as organizações e para os indivíduos, afetando a produtividade, o bem-estar físico-mental e os negócios (Kossek \& Lee, 2017).

Portanto, este artigo contribui teoricamente ao incluir nos debates acerca do conflito trabalho-família as microempreendedoras individuais, um grupo que busca sua consolidação em um mercado cada vez mais competitivo e excludente. De forma prática, auxilia mulheres empreendedoras a buscar estratégias que venham a minimizar os impactos decorridos do conflito de papéis, auxiliando-as em sua tomada de decisão a fim de que possam lidar melhor com as nuances que envolvem a família e os seus negócios.

\section{Referencial teórico}

\subsection{O conflito trabalho-família}

O trabalho é considerado um fator-chave para a saúde e bem-estar dos indivíduos, pois lhes proporciona um meio de ganhar a vida, um sentimento de autorrealização, de provisão às necessidades da família e de ser útil à sociedade (Hemamalini, 2020). Entretanto, as transformações econômicas e culturais advindas da globalização mudaram a vida social em seus 
aspectos profissionais e familiares (Babin Dhas \& Vetrivel, 2020), acentuando os conflitos existentes entre os dois domínios da vida de cada pessoa.

Antes visto como um construto unidimensional, o conflito trabalho-família passou a ser um fenômeno reconhecido como proveniente de qualquer domínio (Clark, 2000). Atinge todos os segmentos sociais e envolve diferentes causas, como o cuidado diário a familiares necessitados, mudanças estruturais, a multiplicidade de papéis e responsabilidades exigidos pelas organizações na economia atual, o que tem feito com que profissionais trabalhem mais tempo (Wibowo, Haryono, \& Nuryakin, 2020), gerando tensões e desafios resultantes da incompatibilidade de expectativas nas diferentes dimensões (Kreiner, Hollensbe, \& Sheep, 2009).

Os conflitos (trabalho-família ou família-trabalho) podem ser considerados perigosos para relações empregado-empregador e empregado-família, uma vez que os conflitos de papéis não afetam apenas a saúde mental dos funcionários, mas também as atitudes negativas relacionadas ao trabalho, como, por exemplo, o desempenho (Shaukat et al., 2017), a satisfação no trabalho e a qualidade das atividades executadas (Ahmad \& Islam, 2019), a criatividade da equipe (Lee et al., 2019), e a intenção de rotatividade (Amiruddin, 2019). Uma vez que família e trabalho são áreas que provocam momentos de satisfação, mas também de conflitos, é necessário identificar estratégias que venham a proporcionar equilíbrio de forma a fazer com que os indivíduos estejam satisfeitos e igualmente envolvidos em seus diferentes papéis (Vampo, 2018), e minimizar os problemas decorrentes dessa relação (Falkenberg, Lindfors, Chandola, \& Head, 2016). Pesquisas mostram, por exemplo, que fatores como o suporte organizacional (Den Dulk et al., 2016), o home office (Sherman, 2019), a satisfação (Hemamalini, 2020) e a motivação para o trabalho podem reduzir os efeitos do conflito trabalho-família no desempenho dos indivíduos (Liang, Wang, Wang, \& Xue, 2018; Wibowo, Haryono, \& Nuryakin, 2020), o que poderia ser aplicado ao empreendedorismo.

Diferentes autores desenvolveram teorias para explicar a maneira como ocorrem os conflitos trabalho-família na literatura. Greenhaus e Beutell (1985) definiram o Conflito Trabalho-Família (CTF) como uma forma de conflito entre papéis em que as pressões de função dos domínios do trabalho e da família são mutuamente incompatíveis em algum aspecto, ou seja, a participação no papel do trabalho é dificultada em virtude da participação no papel da família e a relação inversa também se verifica, o que explica a bidirecionalidade do conflito. Os autores propuseram três dimensões ao fenômeno: I) conflito baseado no tempo, II) conflito baseado em tensão e III) conflito baseado em comportamento. 
Posteriormente, visando contribuir oferecendo uma percepção que fosse além de visões abstratas e metafóricas pouco relevantes para pesquisas mais rigorosas fornecidas por muitas teorias existentes, Edwards e Rothbard (2000) resgatam mecanismos de vinculação nas relações causais entre trabalho e família, classificando-os em: transbordamento, compensação, segmentação, drenagem de recursos, congruência e conflito. Resumidamente, essas categorias mostram que os problemas entre os diferentes domínios podem entrelaçar-se; que os indivíduos podem compensar em um domínio a sua insatisfação com o outro, buscando alívio momentâneo; pode haver separação entre as duas dimensões, não havendo interferência de um domínio sobre o outro; transferência de recursos individuais, como tempo, energia e atenção; por último, pode apresentar incompatibilidade entre os dois domínios, configurando-se em um obstáculo que impede que a cultura vivenciada no ambiente de trabalho possa ser semelhante a experimentada no lar.

As teorias vigentes, até então, preocuparam-se em entender o conflito trabalho-família sob uma ótica causal, sem, necessariamente, propor medidas que viessem a amenizar os impactos negativos nos diferentes domínios. Nesse sentido, Clark (2000) criou a teoria das fronteiras, partindo da premissa de que a relação entre os dois domínios não é emocional, mas humanas, e que as fronteiras existentes entre essas são atravessadas diariamente pelos indivíduos, que moldam suas experiências por meio de atitudes que irão afetar positiva ou negativamente seu equilíbrio. Quatro conceitos centrais são apresentados para entender sua estrutura teórica: a) os domínios trabalho-família; b) as fronteiras entre os domínios; c) o atravessador da fronteira; e d) os guardiões da fronteira e outros membros importantes do domínio. As diversas formas de interação na interface trabalho-vida doméstica orientaram a autora a desenvolver proposições que pudessem proporcionar maior equilíbrio entre os diferentes domínios (Bulger, Matthews, \& Hoffman, 2007), pois entende-se que as pessoas são agentes ativos que definem a força e os limites que facilitarão ou dificultarão seu equilíbrio (Ashfort, Kreiner. \& Fugate, 2000).

Em uma investigação utilizando como base a teoria das fronteiras (Clark, 2000), Kreiner, Hollensbe e Sheep (2009) identificaram quatro táticas possíveis para balancear o trabalho com a vida doméstica. Os autores classificaram como: I) Tática comportamental - é a utilização de habilidades interpessoais e disposição das pessoas próximas ao indivíduo nos diferentes domínios que poderão auxiliá-lo a superar os dois limites em questão; II) Tática temporal - envolve as decisões de como lidar com as questões do tempo em meio às complexidades do trabalho e das responsabilidades familiares; III) Tática física - corresponde à decisão de criar, manter ou flexibilizar as barreiras físicas existentes entre o domínio do 
trabalho e o doméstico; IV) Táticas comunicativas - implica criar estratégias bem definidas de comunicação que visem determinar estratégias e limites a transgressores de fronteiras.

Portanto, para atender o propósito do estudo, este artigo utilizou a teoria da fronteira (Clark, 2000), por entre outros motivos, apresentar, além das complexidades que envolve o fenômeno, proposições que poderão levar a um maior equilíbrio entre os domínios. Esta autora, baseada em estudos, experiências e pesquisa aplicada, propôs, por exemplo, que quando os domínios trabalho-família são semelhantes, maiores graus de flexibilidade, permeabilidade (abertura à influência), identificação e influência por parte dos indivíduos e organizações proporcionarão um maior equilíbrio entre essas dimensões. Seu estudo também constatou a importância dos participantes centrais do domínio (colegas de trabalho, por exemplo) que tem maior consciência sobre a realidade do atravessador de fronteiras em sua outra dimensão, assim como dos seus guardiões (supervisor, pais, cônjuge e filhos) para o sucesso na administração entre as duas dimensões.

\subsection{O conflito trabalho-família no empreendedorismo feminino e as estratégias de enfrentamento em prol de seu equilíbrio}

O empreendedorismo surgiu como uma importante área para o desenvolvimento econômico do Brasil, gerando riqueza e empregos e ajudando a resolver muitos problemas sociais. Porém, o seu gerenciamento é desafiador (Van der Lippe \& Lippényi, 2018); requer dos indivíduos maturidade para lidar com tensões relevantes, exigindo-lhes que possuam recursos físicos, psicológicos e emocionais para enfrentar as adversidades decorrentes de sua atividade (Zhu, Zhou, Lau, \& Wels, 2020). Esse cenário se intensifica quando se trata do público feminino, que precisa, diariamente, conciliar os seus vários papéis no trabalho e na família, muitas vezes de forma desproporcional aos homens (Ahl \& Nelson, 2015; Naldi, Baù, \& Markowska, 2019), mas, que, independentemente das adversidades, as mulheres se veem incentivadas a abrirem seu próprio negócio, na expectativa de que, com maior flexibilidade e controle, possam equilibrar os diferentes domínios (Agarwal \& Lenka, 2015; Thébaud, 2016).

Embora a pesquisa sobre a emergência de oportunidades e a criação de empreendimentos tenha crescido consideravelmente, muito pouca atenção foi dada à forma como a dinâmica familiar afeta os processos empreendedores fundamentais, principalmente no empreendedorismo feminino, pois negócios e famílias são comumente considerados instituições sociais distintas e, como tal, são tipicamente investigados separadamente (Naldi, Baù, \& Markowska, 2019; Zhu, Zhou, Lau, \& Welsh, 2020). Uma pesquisa realizada na 
plataforma de dados Scopus, por exemplo, só identificou (até a data da coleta) dois documentos relacionados à temática considerando os anos de 2005 a 2020, evidenciando a subrepresentação desse público nas agendas de estudos envolvendo empreendedorismo e conflito trabalho-família. Já em buscas nacionais e internacionais em periódicos não indexados à Scopus foi possível encontrar estudos relacionados ao empreendedorismo feminino e o conflito trabalho-família (Bernardi, 2009; Castiblanco Moreno 2016; Ferreira \& Nogueira, 2013; Leite, 2012; Machado, St-cyr, Mione, \& Alves, 2003; Vale, Correa, \& Reis, 2014).

Lee Siew Kim e Ling (2001) estudaram o conflito trabalho-família entre mulheres empresárias casadas de Singapura. Para isso, as autoras dividiram o conflito entre trabalho e família em três partes: conflito cônjuge-trabalho, conflito pais-trabalho e conflito dona de casatrabalho. Como resultado, em termos de fontes de conflito trabalho-família, o número de horas trabalhadas e a inflexibilidade do cronograma teve o maior impacto no conflito pais-trabalho e no conflito dona de casa-trabalho, respectivamente. Foi identificado ainda que os estressores de trabalho têm a maior influência no conflito cônjuge-trabalho e o número de filhos aumenta o nível de conflitos entre pais-trabalho, sendo esse relacionado positivamente à idade dos filhos; e, entre os três tipos de conflito entre trabalho e família, o conflito entre cônjuge e trabalho tem a influência negativa mais significativa no bem-estar das mulheres em termos de satisfação com os negócios, casamento e vida, o que colabora para que o apoio emocional e de atitude dos cônjuges tenha a maior influência na redução do nível de conflito entre trabalho e família das empreendedoras pesquisadas.

De acordo com Jonathan e Silva (2007), há três categorias de situações conflituosas vividas por empreendedoras: conflitos no espaço do trabalho, conflitos entre demandas familiares e profissionais, conflitos entre demandas do trabalho e pessoais; e para amenizar os conflitos, as mulheres recorrem principalmente às seguintes estratégias: auto-organização do tempo, estabelecimento de parcerias e cumplicidade, e uso de dispositivos de alívio e de tensão. Ao estudarem 49 empreendedoras cariocas, as autoras citadas verificaram que o dilema famíliatrabalho não foi destacado por muitas empreendedoras que são mães, por, possivelmente, sentirem-se satisfeitas e autorrealizadas no exercício de múltiplos papéis.

Tendo como base as histórias de vida das empreendedoras participantes do Prêmio SEBRAE Mulher de Negócios em Santa Catarina, os autores Alperstedt, Ferreira e Serafim (2014) analisaram os problemas encontrados ao longo do processo empreendedor. Além dos problemas inerentes ao empreendedorismo, a condição das mulheres contribuiu para o aumento das dificuldades durante a prática empreendedora, exemplo disso é o preconceito, o qual é sentido através da falta de respeito e da credibilidade por parte das pessoas com quem as essas

Revista Gestão e Secretariado (GeSec), São Paulo, SP, 12(2), maio/ago., 2021, 94-121. 
mulheres lidam. Foi destacado ainda o conflito pessoal, familiar e empresarial, sendo estas últimas dimensões divergentes na vida dessas mulheres, pois, de acordo com os relatos das pesquisadas, a maioria concorda que a criação dos filhos está atrelada à mãe na estrutura familiar, o que dificulta a conciliação dos múltiplos papéis.

Strobino e Teixeira (2014), em seu estudo com empresárias do setor de comércio de material de construção, apresentaram os conflitos trabalho-família percebidos e as ações dessas empresárias para lidarem com os conflitos identificados. As autoras constataram que conflitos como indefinição do horário de trabalho, poucas horas dedicadas à família, dificuldades encontradas para o compartilhamento das atividades familiares com os demais membros da família, os quais estão relacionados a dimensão tempo foram mais frequentemente citados como gerador de conflitos trabalho-família.

Floriano (2013) defende que a responsabilidade da mulher em desempenhar vários papéis concomitantemente pode ser capaz de prejudicá-la na intenção de iniciar seu próprio negócio, uma vez que a grande quantidade de responsabilidades assumidas socialmente pelas mulheres exige, inclusive, um direcionamento mais firme com relação ao desejo de ver seu negócio tornar-se real e preparação intelectual para gerenciar sua organização. Esse processo pode desencadear consequências na sua relação com familiares, e seu empreendimento pode exigir uma grande quantidade de tempo e esforço que nem sempre lhe proporcionará o retorno desejado, fato que tenderá a incorrer na sua estabilidade matrimonial, com a criação de filhos e bem-estar individual (Alsos, Carter, Junggren, \& Jørstad, 2016).

A fim de amenizar os impactos resultantes nas fronteiras trabalho-família que empreendedoras atravessaram diariamente, várias pesquisas apontaram estratégias adotadas pelo público, como o controle emocional (Strobino \& Teixeira, 2014), a participação da família nas tomadas de decisões (Lindo et al., 2007; Silva, 2006), o apoio do cônjuge (Alsos, Carter, Junggren, \& Jørstad, 2016; Silva, Mainardes e Lasso (2016), a flexibilização de horários (Lindo et al., 2007), investir em habilidades empreendedoras, como comunicação eficaz, organização, planejamento, liderança e delegação de responsabilidades (Agarwal \& Lenka, 2015).

Shelton (2006) identificou três estratégias básicas para manipular os papéis exercidos para gerenciar conflitos entre trabalho e família: (1) eliminação de papéis; (2) redução da participação num papel; e (3) compartilhamento de papéis. Estas estratégias procuram reduzir o nível de conflito na interface trabalho-família, organizando, sequenciando e delegando atividades de trabalho e família. De acordo com a Shelton (2006), para mulheres ambiciosas, que buscam o crescimento dos seus negócios, as estratégias de eliminação e redução de papéis são implementadas encolhendo o papel da família em vez do trabalho, enquanto mulheres 
menos voltadas para o crescimento podem optar por diminuir as metas de trabalho ou optar por ficar em casa.

Um estudo realizado por Silva, Mainardes e Lasso (2016) mostrou que as empreendedoras pesquisadas expuseram que ser casada afeta positivamente o negócio e o fato de ter um cônjuge não atrapalhou em sua decisão de empreender, podendo até motivá-las e a maioria dessas mulheres classificaram o esposo como o maior apoiador da empreendedora no negócio. Porém, estes autores afirmaram que o principal motivo das mulheres que não estão mais à frente do negócio terem desistido foi por não conseguirem que seus empreendimentos crescessem ou por não terem como dedicar muito do seu tempo ao empreendimento, não tendo tempo para seus afazeres pessoais, como cuidar da casa, da família ou delas mesmas, o que demonstra a dificuldade de conciliar os papéis relacionados ao trabalho e a família.

Em muitas realidades, as mulheres abrem mão de receitas maiores e crescimento para poderem conciliar suas demandas do negócio com as tarefas domésticas, compartimentando seu tempo de trabalho e sua vida pessoal e familiar (Alsos, Carter, Junggren, \& Jørstad, 2016). Porém, os mesmos autores descobriram que elas também recebem apoio moral e dividem mais responsabilidades com seus cônjuges em casa, além de optarem por contratar serviços domésticos para aliviar a sobrecarga com afazeres, contar com a ajuda de familiares para cuidar de seus filhos ou até mesmo levá-los ao trabalho, quando necessário.

Mesmo com o aumento da participação das mulheres no mercado de trabalho, a divisão das responsabilidades familiares entre homens e mulheres, e suas diferentes consequências na vida pessoal e profissional de pais e mães, ainda é bastante desigual (Madalozzo \& Blofield, 2017). Conforme dados do anuário das mulheres empreendedoras 2014 - 2015, considerando a média nacional, $79 \%$ das empregadoras brasileiras e $92,2 \%$ das mulheres que trabalham por conta própria realizam ainda afazeres domésticos. Assim, quando as mulheres experimentam sobrecarga de papéis e recebem apoio normativo inferior por parte dos cônjuges, isso reduz as possibilidade de gestão do seu próprio negócio (Poggesi, Mari, \& De Vita, 2015). Em contraste, bons relacionamentos conjugais e apoio de pais e filhos podem favorecer a um maior espírito empreendedor por meio do suporte familiar, reduzindo os impactos negativos experimentados no trabalho (Zhu et al., 2020), o que mostra que os papéis desempenhados pela família são cruciais para o (in)sucesso no empreendedorismo. 


\section{Metodologia}

\subsection{Descrição da estratégia de pesquisa adotada}

Com a finalidade de alcançar o objetivo proposto, este estudo apresentou natureza descritiva (Prodanov \& Freitas 2013) e abordagem qualitativa (Creswell, 2014). Além disso, assumindo-se uma postura ontológica, em que se acredita que o ser humano é capaz de interagir com a realidade e interpretar um fenômeno de diferentes formas (Morgan \& Smircich, 1980), adotou-se, como metodologia, a fenomenologia (Merriam \& Tisdell, 2015), pois o interesse sobre o tema e como atingir seu objetivo central levou-se em consideração as experiências vivenciadas pelas microempreendedoras individuais e sua relação trabalho-família. Os significados centrais extraídos das entrevistadas sobre o fenômeno investigado foram analisados com base no paradigma interpretativo (Crotty, 1998), o que possibilitou o processo de indução, por parte dos autores, a partir dos dados coletados e sua interpretação (Lincoln \& Guba, 1985).

O estudo foi realizado com 10 microempreendedoras do ramo de confeitaria que atuam na cidade de Natal/RN. Como técnica de coleta de dados, utilizou-se a entrevista semiestruturada (Patton, 2002). Inicialmente, houve dificuldade em obter participantes potenciais para a pesquisa, o que fez com que os pesquisadores adotassem a estratégia da bola de neve (Atkinson \& Flint, 2001), o que foi útil para selecionar o número ideal de empreendedoras por meio da indicação para participar do estudo. Além disso, visando garantir a validade e confiabilidade dos resultados, observou-se o princípio de saturação teórica (Bowen, 2008), sendo possível coletar dados suficientes para a compreensão do fenômeno pesquisado.

As entrevistas ocorreram nos meses de novembro de 2018 e janeiro de 2019, sendo todas gravadas e transcritas e posteriormente submetidas à análise qualitativa de conteúdo temático (Gläser \& Laudel, 2013). Em um processo que envolveu pré-análise, exploração e tratamento dos dados coletados e sua posterior interpretação e inferência (Bardin, 2010), constatou-se que os temais centrais encontrados a priori por meio da literatura apresentada fizeram parte do propósito desse estudo e foram corroborados pela análise proveniente das entrevistas, consolidando categorias conceituais como o conflito trabalho-família, o empreendedorismo feminino e as estratégias de enfrentamento utilizadas. A redução dos dados de forma categórica foi importante para nortear e facilitar o entendimento sobre o fenômeno estudado (Merriam \& Tisdell). 


\subsection{Descrição do perfil sociodemográfico das empreendedoras}

Com a finalidade de apresentar o perfil sociodemográfico das empreendedoras pesquisadas, a Tabela 1 expõe informações acerca da idade, estado civil, quantidade de filhos, escolaridade, renda familiar e tempo no ramo da confeitaria.

Tabela 1

\section{Perfil sociodemográfico das empreendedoras pesquisadas}

\begin{tabular}{ccccccc}
\hline Código & Idade & $\begin{array}{c}\text { Estado } \\
\text { civil }\end{array}$ & Filhos & Escolaridade & Renda familiar & $\begin{array}{c}\text { Tempo como } \\
\text { empreendedora }\end{array}$ \\
\hline E1 & 50 & Solteira & 0 & Superior & $\mathrm{R} \$ 2.000,00$ & 20 anos \\
E2 & 35 & Casada & 2 & Nível médio & $\mathrm{R} \$ 6.000,00$ & 10 anos \\
E3 & 39 & Casada & 3 & Nível médio & $\mathrm{R} \$ 3.5000,00$ & 5 anos \\
E4 & 36 & Casada & 0 & Pós-graduada & $\mathrm{R} \$ 12.000,00$ & 3 anos \\
E5 & 32 & Casada & 1 & Pós-graduada & $\mathrm{R} \$ 3.000,00$ & 1 ano \\
E6 & 48 & Casada & 3 & Superior & $\mathrm{R} \$ 20.000,00$ & 7 meses \\
E7 & 36 & Casada & 1 & Pós-graduada & $\mathrm{R} \$ 5.000,00$ & 1 ano \\
E8 & 42 & Casada & 1 & Pós-graduada & $\mathrm{R} \$ 6.000,00$ & 2 anos \\
E9 & 28 & Casada & 1 & Superior & $\mathrm{R} \$ 6.000,00$ & 2 anos \\
E10 & 29 & Solteira & 0 & Pós-graduada & $\mathrm{R} \$ 10.000,00$ & 5 anos \\
\hline
\end{tabular}

Considerando a idade das entrevistadas, percebe-se que a faixa etária destas variam entre 28 e 50 anos de idade. Constatou-se ainda que a maioria das empreendedoras entrevistadas são casadas e tem pelo menos 1 filho, realidade similar a encontrada na pesquisa de Silva, Mainardes e Lasso (2016). Sobre a escolaridade, 9 das 10 entrevistadas possuem nível superior ou pós-graduação, confirmando os dados do GEM (2017), que expõe que a maioria dos empreendedores brasileiros são graduados ou pós-graduados, o que também é ratificado através dos achados da pesquisa de Silva, Mainardes e Lasso (2016), as quais mostraram que as empreendedoras são mulheres experientes e com nível de escolaridade alto.

A respeito da renda familiar mensal, percebe-se uma significativa variação nos valores apresentados, os quais vão de $\mathrm{R} \$ 2.000,00$ até $\mathrm{R} \$ 20.000,00$. Nota-se ainda que boa parte das participantes da pesquisa possuem renda entre $\mathrm{R} \$ 3.000,00$ e $\mathrm{R} \$ 6.000,00$. De acordo com o que Cisneros (2015) apresenta, a complementação da renda familiar, em virtude da 
complexidade do ambiente econômico nacional e internacional, é um dos principais fatores que contribuem para o avanço da prática empreendedora feminina.

Conforme os estágios de empreendedorismo apresentados pelo GEM 2017, as entrevistadas 4, 5, 6, 7, 8 e 9 são consideradas empreendedoras recentes, uma vez que foi paga alguma remuneração às proprietárias, sob a forma de salário, pró-labore ou outra, por um período superior a três meses e inferior a 42 meses (3,5 anos). Já as entrevistadas 1, 2, 3 e 10, podem ser enquadradas como empreendedoras estabelecidas, devido ao pagamento de alguma remuneração às proprietárias, sob a forma de salário, pró-labore ou outra, por um período superior a 42 meses (3,5 anos).

Questionou-se também qual foi a motivação para a criação do negócio, podendo-se constatar um equilíbrio entre oportunidade e necessidade. $\mathrm{O}$ conhecimento prévio na área da confeitaria e a influência da família, tanto para iniciar no empreendedorismo como em virtude da necessidade de equilíbrio entre as demandas familiares e profissionais, também se apresentaram como motivadores relevantes na realidade das empreendedoras pesquisadas.

De modo geral, as características sociodemográficas das empreendedoras pesquisadas nesse estudo estão em concordância com o exposto em pesquisas acadêmicas e estatísticas que trazem informações a respeito do perfil sociodemográfico de mulheres empreendedoras.

\section{Análise e apresentação dos resultados}

\subsection{O conflito trabalho-família na realidade empreendedora feminina}

Todas as empreendedoras investigadas afirmaram exercer múltiplos papéis unindo aspectos profissionais e familiares, como ser filha, mãe, esposa, avó, neta, dona de casa, confeiteira, empreendedora, dentre outros, que pode gerar conflitos e esgotamento de recursos físicos e mentais (Annor \& Amponsah-tawiah (2017) resultando em riscos para as relações pessoais e para o sucesso do seu empreendimento.

Sobre o nível de envolvimento com a profissão, de acordo com as entrevistadas, o comprometimento com a confeitaria é muito alto, uma vez que os papéis desempenhados no negócio são vários:

Na cozinha quem tá lá vendo os processos, fazendo os processos sou eu, boto a mão na massa mesmo, término lá, venho pra cá. Compras, sou eu que faço. Fornecedor, sou eu que resolvo. Então quer dizer, é total. Então fora a esses papéis da empresa, sou esposa, filha, então tudo isso tenho que administrar, tenho que conciliar (E4). 
Totalmente, $100 \%$. Eu faço tudo. Meu marido me ajuda um pouco nas redes sociais, a questão de estar sempre seguindo as pessoas, porque tem vezes que eu não consigo, não consigo nem olhar. Mas eu faço tudo, eu faço compras, eu faço a produção, eu faço essa parte de marketing, praticamente, instagram $[. .$.$] eu atualizo todo dia. Me$ envolvo totalmente com isso. É minha atividade hoje[...] dedicação total (E9).

Os relatos de E4 e E9 confirmam os achados de pesquisas que mostram que a dinâmica familiar e empresarial é altamente inter-relacionada (Naldi, Baù, \& Markowska, 2019; Zhu, Zhou, Lau, \& Welsh, 2020). E3, E5, E6, E7, E8, E9, E10 trabalham em suas próprias casas. Já E1, E2 e E4 possuem estabelecimentos próprios para a produção e comercialização de seus produtos. De acordo com as entrevistadas 7 e 9, o exercício do trabalho dentro do ambiente familiar facilita na conciliação entre as demandas da família e do trabalho, decorrente da flexibilização de horários favorecida pelo empreendedorismo. E7, por exemplo, diz prazerosa por poder trabalhar e, sempre que possível, dedicar atenção ao filho, deixando-o na escola, fazendo suas refeições, dentre outras coisas. Já E7 e E9 lembram de quando trabalhavam fora, que segundo elas:

\footnotetext{
Agora em casa eu consigo pegar e deixar meu filho na escola, que é algo que eu gosto muito, que me dá muito prazer e ele também gosta. Então eu tou em casa, por mais que eu esteja trabalhando, decorando bolo, mas eu tou de olho, consigo parar pra fazer o almoço dele (E7).
}

Eu já trabalhei em empresa, pra mim é terrível. Eu saía de casa às 06:30 da manhã, só voltava 6:30 da noite, 12 horas fora de casa, não podia resolver nada, não podia ir num médico, não podia fazer nada. Você tem um mês no ano pra fazer tudo que você quiser, então eu consigo fazer tudo hoje. É corrido?! É, mas eu consigo. Consigo levar ele (filho) numa consulta de manhã, consigo levar ele pra escola. É só uma questãozinha de planejamento de tempo (E9).

Tais evidências ratificam o exposto por Floriano (2013), a qual defende que no momento de decidir por abrir ou não sua empresa e em qual ramo se inserir, as mulheres tendem a levar em consideração sua família, buscando ocupações que possibilitem conciliar o aspecto profissional ao pessoal, característica bem menos relevante no mundo masculino. Sobre a aceitação do trabalho por parte do esposo e o apoio dado para que as pesquisadas desenvolvessem suas atividades, a maioria das entrevistadas relatou que há compreensão de seus problemas por parte do cônjuge, e que eles incentivam e colaboram para que elas possam exercer suas atividades profissionais.

A gente tem uma parceria muito grande, então assim há um apoio mútuo. Então ele trabalha, também estuda, então a gente se apoia e tem uma admiração mútua do trabalho, porque aí quando éramos mais novos nós não tivemos essa oportunidade que a gente tem hoje, de trabalhar, de fazer faculdade, hoje é muito mais acessível. Então acaba que a gente tem essa admiração porque a gente dá conta. Com essa idade e com filho, a gente trabalha, estuda, se vira nos 30 (E7). 
A fala de E7 corrobora pesquisas anteriores (Alsos, Carter, Junggren, \& Jørstad, 2016; Silva, Mainardes, \& Lasso, 2016) e condiz com o que Clark (2000) descreve como os "guardiões" da fronteira trabalho-família, demonstrando que o apoio das pessoas que cercam aquele(a) que atravessa os diferentes domínios constantemente é fundamental para o seu equilíbrio. Nesse caso, a entrevistada classificou seu esposo como o maior apoiador em seu empreendimento. Do mesmo modo, Lee Siew Kim e Seow Ling (2001) defendem que o apoio emocional e de atitude dos cônjuges tem a maior influência na redução do nível de conflito entre trabalho e família.

Porém, esse apoio não foi observado em todas as respondentes, pois em alguns casos constatou-se sentimentos de indiferença, incompreensibilidade e não aceitação ao empreendimento por parte da família, em relatos do tipo: "A minha família não aceita bem, entendeu?! Não é que eles não aceitem, eles não falam nada, mas eu sei que eles não se sentem confortáveis em me ver" (E10). E “no início ele era mais insistente, «ah tá trabalhando até tarde». Hoje ele, digamos que, acostumou um pouco, mas ainda pega no pé, tipo, «ah foi pra casa e tá passando a agenda» [...] Ele é realmente sempre meio incompreensível em relação ao trabalho" (E2).

Considerando as falas atrás apresentadas, percebe-se que a atividade profissional exerce influência direta no contexto familiar, seja em relação a falta de compreensão por parte do cônjuge ou de apoio por parte da família. Quando membros do domínio familiar não têm consciência da importância da outra fronteira os conflitos tenderão a acentuar-se (Clark, 2000), podendo reduzir as possibilidades de gestão, resultando em insucesso em médio e longo prazo se não resolvidos a tempo (Poggesi, Mari, \& De Vita, 2015). Olhando para a teoria de fronteiras (Clark, 2000) utilizando a tática comunicativa (Kreiner, Hollensbe e Sheep, 2009) poder-seiam escolher estratégias para amenizar a visão negacionista por parte dos familiares das entrevistadas, definido os limites de fronteiras que estão sendo violados por eles.

No que diz respeito à participação do esposo nas atividades da família e o envolvimento com os filhos, observou-se que a maioria dos esposos das entrevistadas casadas trabalha fora sugerindo-se que a maior parte das responsabilidades do lar recai sobre elas por estarem mais presentes e/ou por trabalhar em casa ou, então, pela própria condição de ser mulher, fator que pode comprometer a conciliação dos diferentes papéis (Alperstedt, Ferreira \&Serafim, 2014). Cabe ressaltar que, para as entrevistadas que são mães, dentre as atividades familiares diárias, a mais citada como prioridade em detrimento ao trabalho, é o cuidado com os filhos: 
eu fazer o meu trabalho, então esses horários assim, almoço, janta, a hora de pôr pra dormir. Às vezes, eu preciso fazer um bolo, prefiro colocar ela pra dormir na hora certa, depois fazer o bolo do que "cortar" isso (E5).

Acho que filho, porque não espera. Tá com fome, não espera, tá com sono, não espera, quer um banho, não espera. Então eu só paro pra isso, pra outra coisa eu não paro. Mas pra isso, você é quase forçada a parar. Ou você para ou ele vai ficar berrando, aí pra isso eu paro (E9).

Pode-se constatar na realidade das entrevistadas, que ainda há certo desequilíbrio em relação à divisão das tarefas familiares (Naldi, Baù, \& Markowska, 2019), uma vez que a responsabilidade sobre tais tarefas é mais incidente para elas do que para os maridos. A divisão das responsabilidades familiares entre homens e mulheres e suas diferentes consequências na vida pessoal e profissional ainda é desproporcional, o que pode reduzir seu desempenho (Shaukat et al., 2017) e a qualidade das atividades executadas (Ahmad \& Islam, 2019), principalmente quando envolve a criação dos filhos, em que as mulheres carregam um ônus maior das responsabilidades (Ahl \& Nelson, 2015; Madalozzo \& Blofield, 2017; Sherman, 2019). Quando questionadas sobre se ter filhos influencia no desempenho profissional, a maioria das entrevistadas expôs que os filhos afetam positivamente no exercício da profissão, motivando-as a iniciar e manter seus negócios. Porém, por ser mais um papel a ser desempenhado, o tempo a ser dedicado a profissão termina por ser afetado, sendo necessário recorrer ao apoio de outras pessoas para poder conciliar as atividades.

Assim[...]. Quando se tem um suporte, como eu tenho minha mãe que me dá esse suporte, as meninas meio que não atrapalham não. Não vou mentir pra você não, estaria sendo hipócrita. Mas[...] é uma preocupação, filho é sempre uma preocupação (E2).

Talvez[...] com certeza. Filho influencia em tudo, dá uma mudada na sua vida que com certeza influencia. Se eu não tivesse ele, talvez eu tivesse mais tempo. Então com certeza influencia, talvez se eu não tivesse filho, talvez eu tivesse um pouquinho mais de tempo (E9).

Nos casos das entrevistadas 1 e 10, apesar de não terem filhos, recai sobre elas o cuidado com a mãe e com o avô, respectivamente, sendo essas as atividades familiares prioritárias para elas.

Ficar com meu avô. Pra isso, eu atraso a produção, eu entro na madrugada, mas se eu tiver que ficar a manhã com ele, eu fico. Minha agenda é feita de acordo com a necessidade da família. Minha avó precisa sair com a minha mãe, eu fico com o meu avô. Eu só posso atender uma noiva quando meu avô estiver acompanhado, que eu atendo na sala de casa $(\mathrm{E} 10,2019)$.

Lee Siew Kim e Seow Ling (2001) defendem que o número de filhos aumenta o nível do conflito trabalho-família. Contudo, não se pode afirmar que, por não terem filhos, as 
entrevistadas 1 e 10 vivenciam um nível de conflito inferior quando comparadas àquelas que os possuem. Apesar de não exercerem o papel de mãe, elas exercem o papel de cuidadora, sendo necessário conciliar as demandas desse papel com o empreendedorismo. Desse modo, observase que é nítida a interferência da família na dinâmica dos negócios e dessa dinâmica no contexto familiar, o que pode levar a geração de demandas conflitantes e consequentemente, ao conflito entre trabalho e família (Ferreira \& Nogueira, 2013). Evidencia-se ainda que as situações vivenciadas exemplificam o exposto por Castiblanco Moreno (2016), que explicita que na cultura ocidental, a tradição patriarcal costuma ver as mulheres como agentes responsáveis pela prestação de cuidados aos membros das famílias.

Igualmente, foi levantado o questionamento se o fato de ser empreendedora deixava a vida familiar mais difícil ou mais fácil. A maioria das entrevistadas afirmou que o empreendedorismo facilita a vida familiar, principalmente em virtude da flexibilização de horários, espelhando pesquisas anteriores (Bernardi, 2009; Castiblanco Moreno, 2016; Machado, St-cyr, Mione, \& Alves, 2003; Vale, Correa, \& Reis, 2014). Todavia, conforme as entrevistadas 5 e 8, ser dona do próprio negócio aumenta as responsabilidades, tanto em relação a contribuição financeira para a renda familiar, como também em impulsionar o negócio para que ele cresça e se estabeleça no mercado.

Com base na teoria de Clark (2000), a fronteira que mais acentua o conflito trabalhofamília, segundo as entrevistadas, é a temporal, indicando que a incompatibilidade de horários compromete o tempo que se desejaria dedicar à família, uma vez que esse fator gasto em atividades dentro de um papel pode comprometer outras áreas de sua vida, achado que é reforçado pelos seguintes relatos:

Eu me envolvo totalmente, de segunda a segunda. Assim, é um ramo bem[...] precisa gostar, porque não tem feriado, não tem férias, não tem descanso, fim de semana, é direto. Porque quando a gente trabalha, as pessoas estão se divertindo, nas festas, no fim de semana (E1).

Nós que trabalhamos nessa área de confeitaria, você bem tem que dizer "Adeus!" a questões de finais de semana, um lazer. Que é muito difícil, festa é no final de semana, então a gente tem que está na disponibilidade do cliente. Existe muito isso, então as vezes eles saem, mas saem só com o pai. Então há muito essa reclamação dos filhos: "ah mãe, você nunca tem tempo pra mim". Sempre tem esse porém. (E3).

Essas evidências confirmam estudos anteriores (Silva et al., 2016; Strobino \& Teixeira, 2014) reforçando como o tempo pode afetar os diferentes domínios entre empreendedorismo e família. Ao demonstrar que o trabalho não lhes permite, na maioria das vezes, dedicar momentos propícios para lazer com entes queridos, as referidas entrevistadas podem estar potencialmente suscetíveis a experimentar problemas em suas relações no lar, uma vez que suas

Revista Gestão e Secretariado (GeSec), São Paulo, SP, 12(2), maio/ago., 2021, 94-121. 
atenções demasiadas podem levar a queixas constantes dos filhos e divórcio, se não administrados eficazmente. Nesse sentido, uma maior gestão de fronteiras combinando permeabilidade e flexibilidade poderia fortalecer o equilíbrio entre os domínios, por exemplo, ao permitir que os filhos possam frequentar mais o espaço organizacional ao mesmo tempo em que essas empreendedoras destinariam um pouco mais do seu tempo para seu lazer, aumentando, assim as interações familiares (Clark, 2000). Outro tipo de permeabilidade seria em relação ao fator físico, que seria o exercício das atividades profissionais dentro de suas próprias casas. Conforme já exposto anteriormente, algumas entrevistadas afirmaram que isso facilita na conciliação entre as demandas da família e do trabalho, embora essa opinião contraste com autores que acreditam que nem sempre essa proximidade do trabalho com a família poderá ser positiva (Van der Lippe \& Lippényi, 2018). Esse entendimento pôde ser constatado por outras participantes do estudo, que mencionaram algumas dificuldades em se ter os domínios familiares e profissionais em um mesmo ambiente:

Tem dias que, por exemplo, hoje tá tranquilo, mas tem dia que eu trabalho de 6 da manhã a 2 da manhã, entendeu?! Assim, e como você trabalha em casa, não tem isso: «ah eu vou fechar a empresa e vou pra casa.» É tudo ligado, você acaba fazendo uma coisa mais tarde, adiantando um trabalho (E5).

Eu acho que o principal problema do meu negócio é ele estar dentro de casa, porque a partir do momento que ele tiver cara de empresa, porque pra minha família não tem, apesar de pra mim ser uma empresa, de ter tabela de custos, de tudo, de entrada $\mathrm{e}$ saída, de ser super organizada, pra minha família é só uma espécie de bico (E10).

O conflito trabalho-família demonstra uma relação bidirecional, em que o trabalho interfere na família e a família interfere no trabalho. Mesmo para aquelas que possuem estabelecimento próprio, ainda assim, há dificuldade em separar os dois âmbitos, conforme cita a entrevistada 2: "Sim, as vezes eu trago coisa de lá pra cá, acontece, meio que mistura. Não tem um limite". Para E2 e E8, o principal conflito identificado foi o baseado em tensão. A E2 acredita que quem trabalha no ramo da confeitaria abdica muitas vezes da família, e na situação dela, em específico, não há apoio e compreensão por parte do cônjuge em relação ao desempenho das atividades profissionais e familiares, o que ajuda para que a rotina de trabalho se torne estressante e que os problemas do trabalho interfiram no contexto familiar. Da mesma forma, a E8 considera o dia a dia no trabalho bastante estressante e por perceber que se envolve mais com as atividades do trabalho do que o cônjuge.

Sobre a realidade da E10, constata-se que o principal conflito identificado está relacionado à dimensão comportamental (Clark, 2000). Ou seja, enquanto no trabalho esperase que a mulher adote um comportamento prático e ordenado, a família, por sua vez, espera que 
ela haja com gentileza, docilidade, compreensão e carisma (Strobino \& Teixeira, 2014). A entrevistada 10 tem sua própria mãe como funcionária do seu negócio e para ela essa é uma situação que interfere nos contextos profissionais e familiares:

\begin{abstract}
Complicado, é muito complicado. Porque eu tenho 29 anos e minha mãe tem 48, ela é muito jovem. Mas assim eu tenho que me colocar na situação de ser a responsável pela empresa. Então assim, qualquer coisa que acontecer, de execução de contrato, de ter algum vício, alguma dificuldade, a responsável sou eu. Então eu tenho que exigir bastante e eu não alivio e isso realmente dá uma abalada familiar. Quando eu vejo pequenas coisas erradas, assim[...] é muito difícil ser mulher e ser chefe, ainda mais ser chefe da mãe. Então eu tenho que saber o que pode ser dito no núcleo familiar e o que não pode ser dito e administrar tudo isso (E10).
\end{abstract}

Considerando a fala acima, nota-se a necessidade que a entrevistada tem em separar o papel de chefe e de filha, os quais, quando se confundem, geram conflitos no trabalho e na família. Kreiner, Hollensbe e Sheep (2009) asseveram que é necessário, nesses momentos, ter uma habilidade maior de relacionamento interpessoal, o que pode ser uma boa tática para equilibrar os domínios trabalho-família.

Mesmo com os conflitos vivenciados, as pesquisadas expuseram a motivação, a busca pelo aperfeiçoamento e o sentimento de realização em ser empreendedora e trabalhar com a confeitaria. Falas como "Me sinto realizada. Estou mais realizada do que quando trabalhava com TI" (E5), ou "Quando a gente faz o que a gente gosta, já tem uma motivação. Então eu estou trabalhando com o que eu gosto" (E4), ou"Meu trabalho de uma maneira geral é muito motivador, porque eu não vendo só doce, eu vendo sonho, é a realização" (E7), ou ainda "Eu saí de um processo depressivo muito delicado e eu ganhei autoestima com a empresa, com a confeitaria. Eu digo isso sem medo nenhum, que a confeitaria me salvou" (E10); mostram que no empreendedorismo feminino a motivação e a realização do negócio estão presentes na prática empreendedora (Bernardi, 2009; Jonathan \& Silva, 2011; Leite, 2012; Lindo et al., 2007; Vale, Correa \& Reis, 2014).

\title{
4.3 Estratégias adotadas para lidar com o conflito trabalho-família
}

Considerando que a teoria de fronteiras (Clark, 2000) tem como um de seus maiores propósitos um maior equilíbrio trabalho-família, constatou-se que o compartilhamento de papéis tem sido uma das estratégias mais utilizadas pelas empreendedoras entrevistas. Dessa forma, as empreendedoras podem delegar partes do seu papel profissional empregando técnicas de gestão participativa e investindo em treinamento, remuneração competitiva e outras práticas progressistas de recursos humanos para capacitar os subordinados e formar equipes; da mesma

Revista Gestão e Secretariado (GeSec), São Paulo, SP, 12(2), maio/ago., 2021, 94-121. 
maneira, parcelas do papel da família podem ser delegadas por meio da contratação de assistência para cuidar de crianças e tarefas domésticas, ou buscando a ajuda de parentes e amigos (Shelton, 2006).

Analisando as realidades das entrevistadas, todas compartilham as atividades familiares, como o cuidado com os filhos e/ou as tarefas domésticas com os demais membros da família, principalmente com o esposo e com a mãe:

Minha mãe que fica com minhas filhas o tempo todo. Ela me dá um apoio sim. Se não fosse ela, ficava mais difícil. Ela é que é meu suporte. Em casa, ela praticamente que toma conta das meninas e dá essa ajuda. Se não fosse, realmente fica difícil pra quem trabalha e tem que voltar pra casa (E2).

Meu esposo, ele me acompanha, me ajuda. Na hora que precisa dos deveres de casa, ele chega junto e ajuda. A gente compartilha, divide muito isso né?! E aí, assim, pronto, final de semana as vezes ele diz: «Ah, você passa a semana na cozinha, vamos comer fora!».Mas ah, não acho ruim, vou, faço. Então a gente divide, então tem muito esse companheirismo (E4).

O apoio dos pais e cônjuges presentes nesses relatos reforça o papel que os guardiões das fronteiras (Ashfort, Kreiner, \& Fugate, 2000; Clark, 2000; Kreiner, Hollensbe, \& Sheep, 2009) desempenham para que as atravessadoras (empreendedoras) possam equilibrar seus domínios trabalho-família e amenizar suas tensões. Shelton (2006) argumenta que as estratégias de gestão de trabalho familiar são um determinante significativo para o crescimento do negócio e que as estratégias de compartilhamento de papéis são preferidas pela maioria das mulheres, porque essas opções permitem que elas desfrutem do aprimoramento das funções de trabalho e família e reduzam o nível de conflito.

Em relação às atividades profissionais, apenas E1, E2, E4 e E10 compartilham o desempenho dessas atividades com funcionários ou terceiros, enquanto as demais entrevistadas concentram em si várias funções do negócio, como produção, compras, organização de encomendas, divulgação, entre outras. Com isso, é possível que essas mulheres tenham mais dificuldade em reduzir o nível de conflito, em virtude dos muitos papéis exercidos no negócio, os quais ainda são conciliados com os papéis familiares.

Uma outra estratégia citada para atenuar os conflitos foi a organização do tempo:

Eu tento uma organização com o tempo. Se eu já tiver uma agenda pré-organizada, já com antecedência, sim, eu consigo organizar. Mas acontece muito de encomenda de última hora e aí eu paro que estiver fazendo dentro de casa e vou fazer essa encomenda. Quando eu já estou organizada, não, eu já consigo fazer. De manhã, eu tou com meu filho, faço a atividade da escola com ele, organizo as coisas de casa, coloco ele na escola e pronto, a tarde vou produzir (E7). 
Reiterando o que foi exposto pelas entrevistadas, a pesquisa realizada por Strobino e Teixeira (2014) cita que, dentre algumas ações que mulheres empreendedoras utilizam para lidar com os conflitos trabalho-família, está o controle do tempo dedicado ao trabalho e à família e a divisão das atividades domésticas com os demais membros da família.

Percebe-se que as estratégias utilizadas pelas empreendedoras confeiteiras para atenuar os conflitos entre o trabalho e a família vão ao encontro do que é exposto pelas principais pesquisas apresentadas no referencial teórico deste estudo, que atestam que o compartilhamento de papéis e uma melhor organização do tempo estão entre as estratégias mais empregadas para minimizar o conflito trabalho-família.

\section{Considerações Finais}

Este artigo teve como objetivo compreender como o conflito trabalho-família impacta o empreendedorismo feminino. Foram expostas as dificuldades enfrentadas pelas mulheres empreendedoras, tanto para a abertura do novo negócio quanto para o estabelecimento dos empreendimentos, como obtenção de financiamento, conciliação entre o trabalho e a família, concorrência, custo de matéria prima e a manipulação de alimentos.

Sobre os conflitos trabalho-família percebidos, todas as entrevistadas apontaram que vivenciam algum nível de conflito entre os âmbitos pessoais e profissionais e que as fronteiras temporais e físicas foram identificadas com as menos permeáveis e desafiadores. Em virtude do desempenho de múltiplos papéis, o tempo gasto no desempenho de um determinado papel acaba por influenciar o exercício das atividades dentro de outro papel, gerando assim o conflito. Por vivenciarem uma realidade que lhes permite maior autonomia para tomar decisões, as empreendedoras, na qualidade de atravessadoras de fronteiras, têm a oportunidade de repensarem seus domínios, a fim de negociar e realizar as mudanças necessárias para que haja maior flexibilidade e permeabilidade entre os diferentes papéis. O apoio dos pais e dos cônjuges como guardiões da fronteira pode ser primordial para o alcance desse equilíbrio.

Já o exercício das atividades profissionais dentro da própria casa, mesmo facilitando na conciliação entre as demandas da família e do trabalho, também gera dificuldades em separar os dois âmbitos. Há de referir-se aqui, mais uma vez, a importância da permeabilidade entre fronteiras (Clark, 2000; Kreiner et al., 2009) com a fronteira familiar a ser mais permeável a intrusões do trabalho na família, pelo simples fato de o «lar» constituir-se como o espaço simultâneo das duas atividades: a familiar e a do negócio empreendedor. 
O estudo contribuiu para o conhecimento científico ao aprofundar as discussões sobre o conflito trabalho-família no empreendedorismo, especificamente o feminino, sob a lente da teoria das fronteiras (Clark, 2000), que não está preocupada apenas em analisar as causas para o fenômeno, mas também em estabelecer estratégias para um maior equilíbrio. De forma prática, auxiliará as mulheres empreendedoras a buscar estratégias capazes de gerir melhor seus negócios e a vida familiar.

Dentre as limitações do estudo, registra-se o fato de, por ser uma pesquisa qualitativa, seus resultados não se generalizarem, estatisticamente, a outras realidades, embora, possam ser replicáveis em outros contextos culturais. Por isso, como sugestão para futuras investigações, propõe-se a realização de novos estudos que possam avançar na temática, trazendo abordagens quantitativas, buscando novas relações a fim de que novas estratégias de lidar com o conflito não interfiram na consecução dos objetivos de crescimento no empreendedorismo. Além disso, mostra-se a necessidade de pesquisas que contrastem a realidade de homens e mulheres empreendedores, buscando analisar as semelhanças e diferenças das perspectivas de cada gênero sobre a temática.

\section{Referências}

Agarwal, S. \& Lenka, U. (2015). Study on work-life balance of women entrepreneurs - review and research agenda. Industrial and Commercial Training, 47(7), 356-362.

Ahmad, R., \& Islam, T. (2019). Does work and family imbalance impact the satisfaction of police force employees? A "net or a web" model. Policing: An International Journal. doi:10.1108/pijpsm-05-2018-0061.

Ahl, H., \& Nelson, T. (2015). How policy positions women entrepreneurs: A comparative analysis of state discourse in Sweden and the United States. Journal of Business Venturing, 30(2), 273-291.

Alperstedt, G. D., Ferreira, J. B., \& Serafim, M. C. (2014). Empreendedorismo Feminino: dificuldades relatadas em histórias de vida. Revista de Ciências da Administração, p.221234, 16. Doi:10.5007/2175-8077.2014v16n40p221.

Alsos, G. A., Ljunggren, E., Carter, S., Jørstad, M. O. (2016). Women, Family and Entrepreneurship: Strategies for Managing Work-life Balance Challenges. Academy of Management Annual Meeting Proceedings, 1:16079. doi: 10.5465/AMBPP.2016.16079abstract 
Amiruddin, A. (2019). Mediating effect of work stress on the influence of time pressure, workfamily conflict and role ambiguity on audit quality reduction behavior. International Journal of Law and Management, 00-00. doi:10.1108/ijlma-09-2017-0223.

Annor, F., \& Amponsah-Tawiah, K. (2017). Evaluation of the psychometric properties of two scales of work-family conflict among Ghanaian employees. The Social Science Journal, 54(3), 336-345. doi:10.1016/j.soscij.2017.04.006.

Ashforth, B. E., Kreiner, G. E., \& Fugate, M. (2000). All in a day's work: Boundaries and micro role transitions. Academy of Management Review, 25, 472-491.

Atkinson, R., \& Flint, J. (2001). Accessing hidden and hard-to-reach populations: Snowball research strategies. Social research update, 33(1), 1-4.

Babin Dhas, D., \& Vetrivel, S. C. (2020). Substantiate the intervention effect of work-life balance in SME's with special reference in Chennai. Test Engineering and Management, 83(30), 17769-17781.

Bardin, L. (2010). Análise de conteúdo. São Paulo: Edições 70.

Bernardi, L. A. (2009). Manual de Empreendedorismo e Gestão: Fundamentos, estratégias e dinâmicas. 1. Ed. São Paulo: Atlas.

Bowen, G. A. (2008). Naturalistic inquiry and the saturation concept: a research note. Qualitative Research, 8(1), 137-152.

Bulger, C. A., Matthews, R. A., \& Hoffman, M. E. (2007). Work and Personal Life Boundary Management: Boundary Strength, Work/Personal Life Balance, and the SegmentationIntegration Continuum. Journal of Occupational Health Psychology, 12(4), 365-375.

Castiblanco Moreno, S. E. (2016). Female entrepreneurship in a forced displacement situation: The case of Usme in Bogota. Suma de Negocios, 7(15), 6172. doi:10.1016/j.sumneg.2016.02.004.

Cisneros, M. E. E. (2015). Desempeño de nuevos negocios: perspectiva de género. Contaduría y Administración, 60(2), 468-485. doi: 10.1016/S0186-1042(15)30010-3.

CNDL; SPC BRASIL. O Perfil das micro e pequenas empresas brasileiras: Junho, 2015. Disponível em: https://www.spcbrasil.org.br/uploads/st_imprensa/relatorio_perfil_mpe1.pdf. Acesso em 02 de julho de 2019.

Clark, S. C. (2000). Work/family border theory: A new theory of work/family balance. Human Relations, 53, 747-770. 
Creswell, J. W. (2014). Investigação qualitativa e projeto de pesquisa: escolhendo entre cinco abordagens/ John W. Creswell; tradução: Sandra Mallmann da Rosa; revisão técnica: Dirceu da Silva. - 3. ed. - Dados eletrônicos. - Porto Alegre: Penso.

Crotty, M. (1998). The foundations of social research: meaning and perspective in the research process. Crows Nest: Sage Publications Ltd.

Den Dulk, L., Peper, B., Kanjuo Mrčela, A., \& Ignjatović, M. (2016). Supervisory support in Slovenian and Dutch organizations: a contextualizing approach. Community, Work \& Family, 19(2), 193-212.

Edwards, J., \& Rothbard, N. (2000). Mechanisms linking work and family: Clarifying the relationships between work and family constructs. Academy of Management Review, 25(1), 178-199.

Falkenberg, H., Lindfors, P., Chandola, T., \& Head, J. (2016). Do gender and socioeconomic status matter when combining work and family: Could control at work and at home help? Results from the Whitehall II study. Economic and Industrial Democracy, 41(1), 2954. doi: $10.1177 / 0143831 \times 16682307$.

Ferreira, J. M., \& Nogueira, E. E. S. (2013). Mulheres e suas histórias: razão, sensibilidade e subjetividade no empreendedorismo feminino. Revista de Administração Contemporânea, 17(4), 398-417. doi: 10.1590/S1415-65552013000400002.

Floriano, L. E. de F. (2013). Empreendedorismo Feminino: motivações, significados e desdobramentos. Relatório de pesquisa (Programa Institucional de Bolsas de Iniciação Científica (PIBIC) do CNPq/GVpesquisa) - Escola de Administração de Empresas, Fundação Getúlio Vargas, São Paulo.

Gläser, J. \& Laudel, G. (2013). Life with and without coding: two methods for early-stage data analysis in qualitative research aiming at causal explanation. Forum Qualitative Social Research, 14(2). Disponível em: www.qualitativeresearch.net/index.php/fqs/article/view/1886. Acesso em 12 de maio de 2020.

Global Entrepreneurship Monitor. Empreendedorismo no Brasil: Relatório executivo 2017. Disponível em: https://m.sebrae.com.br/Sebrae/Portal\%20Sebrae/Anexos/Relat\%C3\%B3rio\%20Executiv o\%20BRASIL_web.pdf. Acesso em: 01 de junho de 2018.

Greenhaus, J. H., \& Beutell, N. J. (1985). Sources of conflict between work and family roles. Academy of Management Review, 10(1), 76-88. 
Hemamalini, R. (2020). An integrative model to explore the relationship of work-family interface with organisational commitment. International Journal of Human Resources Development and Management, 20(2), 166. doi:10.1504/ijhrdm.2020.106288.

Jonathan, Eva G., \& Silva, T. M. R. da. (2007). Empreendedorismo feminino: tecendo a trama de demandas conflitantes. Psicologia \& Sociedade, 19(1), 77-84. doi: 10.1590/S010271822007000100011 .

Kossek, E., \& Lee, K-H. (2017). Work-Family Conflict and Work-Life Conflict. Oxford Research Encyclopedia of Business and Management. Disponível em: http://busi ness.oxfordre.com/view/10.1093/acrefore/97801902 24851.001.0001/acrefore9780190224851-e-52. Acesso em 29 de maio de 2020.

Kreiner, G.E., Hollensbe, E.C., \& Sheep, M.L. (2009). Balancing borders and bridges: Negotiating the work-home interface via boundary work tactics. Academy of Management Journal, 52(4), 704-30.

Lee Siew Kim, J., \& Seow Ling, C. (2001). Work-family conflict of women entrepreneurs in Singapore. Women in Management Review, 16(5), 204-221. doi: 10.1108/09649420110395692.

Lee, E.K., Avgar, A.C., Won-Woo, P. and Choi, D. (2019). The dual effects of task conflict on team creativity. International Journal of Conflict Management, 30(1), 132-154.

Leite, E. (2012). O fenômeno do empreendedorismo. São Paulo: Saraiva.

Liang, H., Wang, M.-M., Wang, J.-J., \& Xue, Y. (2018). How intrinsic motivation and extrinsic incentives affect task effort in crowdsourcing contests: A mediated moderation model. Computers in Human Behavior, 81, 168-176. doi:10.1016/j.chb.2017.11.040.

Lincoln, Y. S.; Guba, E. G. (1985). But is it rigorous? Trustworthiness and authenticity in naturalistic evaluation. In: Williams, D. D. Ed. Naturalistic evaluation, new directions for program evaluation, n.30. San Francisco; Jossey-Bass, 1985.

Lindo, M. R., Cardoso, P. M., Rodrigues, M. E., \& Wetzel, U. (2007). Vida pessoal e vida profissional: os desafios de equilíbrio para mulheres empreendedoras do Rio de Janeiro. RAC-Eletrônica, 1(1), 1-15.

Machado, H. V.; St-Cyr, L., Mione, A., \& Alves, Marcia Cristina Moita. (2003). O processo de criação de empresas por mulheres. RAE eletrônica,2(2). doi: 10.1590/S167656482003000200007.

Madalozzo, R., \& Blofield, M. (2017). Como famílias de baixa renda em São Paulo conciliam trabalho e família?. Revista Estudos Feministas, 25(1), 215-240. doi:10.1590/18069584.2017v25n1p215.

Revista Gestão e Secretariado (GeSec), São Paulo, SP, 12(2), maio/ago., 2021, 94-121. 
Merriam, S. B. \& Tisdell, E. J. (2015). Qualitative research: A guide to design and implementation. John Wiley \& Sons.

Morgan, G.; Smircich, L. (1980). The case for qualitative research. Academy of Management Review, v.5, p.491-500.

Nambisan, S., \& Baron, R. A. (2019). On the costs of digital entrepreneurship: Role conflict, stress, and venture performance in digital platform-based ecosystems. Journal of Business Research. doi:10.1016/j.jbusres.2019.06.037.

Naldi, L., Baù, M., Ahl, H. et al. (2019). Gender (in) equality within the household and business start-up among mothers. Small Business Economics. https://doi.org/10.1007/s11187-01900275-1

Patton, M. (2002). Qualitative research and evaluation methods. Londres, Thousand Oaks: Sage Publications.

Poggesi, S., Mari, M., \& De Vita, L. (2015). Family and work-life balance mechanisms: what is their impact on the performance of Italian female service firms? International Journal of Entrepreneurship and Innovation 16(1):43-53. doi: 10.5367/ijei.2015.0173.

Prodanov, c. c., \& Freitas, E. C. (2013). Metodologia do trabalho cientifico: métodos e técnicas da pesquisa e do trabalho acadêmico. 2. ed. Novo Hamburgo: Feevale.

Shaukat, R., Yousaf, A. and Sanders, K. (2017). Examining the linkages between relationship conflict, performance and turnover intentions. International Journal of Conflict Management, 28(1), 4-23.

Shelton, L. M. (2006). Female Entrepreneurs, Work-Family Conflict, and Venture Performance: New Insights into the Work-Family Interface*. Journal of Small Business Management, 44(2), 285-297. doi:10.1111/j.1540-627x.2006.00168.x.

Sherman, E. L. (2019). Discretionary Remote Working Helps Mothers Without Harming Nonmothers: Evidence from a Field Experiment. Management Science. doi:10.1287/mnsc.2018.3237.

Silva, L. A. da., Bandeira, E. L., Santos, S. M. dos., Lima, T. C. B. de., \& Cabral, A. C. de. A. (2016). O conflito trabalho-família vivenciado por mulheres empreendedoras do setor de confecção. Revista Encontros Universitários da UFC, 1(1).

Silva, M. S. da; Mainardes, E. W., \& Lasso, S. V. (2016). Características do Empreendedorismo Feminino no Brasil. Revista Gestão e Desenvolvimento, Novo Hamburgo, 13(2), 150-167. Silva, P. M. M. da., El-Aouar, W. A., Silva, A. W. P. da., Castro, A. B. C. de., \& Sousa, J. C. de. (2019). A resiliência no empreendedorismo feminino. Revista Gestão \& Sociedade, 13(34), 2629-2649, jan-abr. doi: 10.21171/ges.v13i34.2346.

Revista Gestão e Secretariado (GeSec), São Paulo, SP, 12(2), maio/ago., 2021, 94-121. 
Strobino, M. R. de C., \& Teixeira, R. M. (2014). Empreendedorismo feminino e o conflito trabalho-família: estudo de multicasos no setor de comércio de material de construção da cidade de Curitiba. Revista de Administração (São Paulo), 49(1), 5976. https://doi.org/10.5700/rausp1131.

Teoh, W. M-Y., Chong, C. W., Chong, S. C., \& Ismail, H. (2016). Managing work-family conflict among entrepreneurs: An Empirical Study. International Journal of Business and Management; 11(9). doi: 10.5539/ijbm.v11n9p179.

Thébaud, S. (2016). Passing Up the Job: The Role of Gendered Organizations and Families in the Entrepreneurial Career Process. Entrepreneurship Theory and Practice, n/a-n/a.

Vale, G. M. V.; Corrêa, V. S., \& Reis, R. F. dos. (2014). Motivações para o empreendedorismo: necessidade versus oportunidade?. Revista de Administração Contemporânea, 18(3), 311327. doi: 10.1590/1982-7849rac20141612.

Vampo, C. (2018). Female business leaders and young female entrepreneurs in lomé (Togo): The double life of "superwomen" and their domestic burdens. Enfances, Familles, Generations, 29.

Van der Lippe, T., \& Lippényi, Z. (2018). Beyond Formal Access: Organizational Context, Working From Home, and Work-Family Conflict of Men and Women in European Workplaces. Social Indicators Research. doi:10.1007/s11205-018-1993-1

Wibowo, F. N., Haryono, S., \& Nuryakin. (2020). Evaluating the effect of work-family conflict on work stress and employee performance: the moderation role of motivation. International Journal of Advanced Science and Technology, 29(6), 3690-3697.

Zhu, W., Zhou, J., Lau, W. K., \& Welch, S. (2020). How harmonious family encourages individuals to enter entrepreneurship: A view from conservation of resource theory. International Journal of Conflict Management, 31(3), 333-351. doi: 10.1108/IJCMA-092019-017d. 


\section{ANEXO 1 - ROTEIRO DE ENTREVISTA}

1. Experiência profissional pessoal anterior à abertura da empresa?

2. Quanto tempo tem sua empresa?

3. Quando surgiu a ideia de abrir a empresa?

4. Se não é herança familiar, como surgiu a ideia de ter sua própria empresa (motivações)?

5. Quais as dificuldades encontradas para a abertura da empresa?

6. Qual o grau de envolvimento com a organização?

7. Quais as funções (papéis) que você tem (profissionais, familiares e pessoais)?

8. Há percepção da existência de incompatibilidades entre o trabalho e a família?

9. Se a resposta for afirmativa, a que podem ser atribuídas essas incompatibilidades?

10. A flexibilidade de horários, por ser dona do próprio negócio, colabora ou piora com a organização das tarefas diárias, tanto familiares quanto profissionais?

11. As atividades familiares são compartilhadas (delegadas à terceiros ou a outros membros da família)?

12. A empresa possui estratégia de gestão? Você buscou auxílio de alguma consultoria empresarial ou de algum órgão de apoio como o SEBRAE? Você acha que ajuda/ajudaria a conciliar o trabalho e a família?

13. As funções/atividades da família prejudicam o desempenho profissional? Prejudicam a organização?

14. As funções/atividades do trabalho prejudicam a família? Prejudicam a harmonia do lar?

15. O marido também percebe a existência de conflito trabalho-família?

16. As atividades do trabalho do marido geram conflito em casa? E as atividades familiares geram conflito no trabalho do marido?

17. O marido concorda/aceita seu trabalho?

18. Na sua opinião (palavras da empreendedora), como seu marido "vê" o seu trabalho? Como ele a "vê" como profissional? Como ele a "vê" como esposa? Como ele a "vê" como mãe?

19. Como você "vê" o trabalho do marido? Como o "vê" como profissional? Como o "vê" como marido? Como o "vê" como pai?

20. O fato de ter filhos, na sua opinião, prejudicou(a) o desempenho profissional?

21. O fato de ser dona da empresa, ter seu próprio negócio, deixa a vida familiar mais difícil? 
22. A dedicação à empresa é maior e isso deixa a família 'abandonada'. Essa afirmação pode ser considerada verdadeira?

23. O seu envolvimento com os filhos é maior do que o envolvimento do marido? Se sim, isso faz com que sua dedicação ao trabalho seja menor do que a dedicação de seu marido ao trabalho dele?

24. Você sente que o marido participa das atividades familiares na mesma intensidade que você? Você cobra a participação do marido nas atividades domésticas?

25. A rotina no trabalho é desmotivadora? Ou seja, você sente que faz sempre a mesma coisa e isso lhe dá a sensação de que não há um desempenho positivo da organização? O dia-a-dia no trabalho pode ser considerado estressante?

26. Os problemas do trabalho, como discussões com funcionários, fornecedores ou clientes, fluxo de caixa, prazos de entrega de produtos ou serviços, entre outros, alteram seu relacionamento com os membros de sua família? Você leva os problemas do trabalho para casa?

27. Você leva os problemas da família para o trabalho? Se sim, esses problemas alteram seu relacionamento com membros da empresa, clientes e fornecedores?

28. Você percebe no cônjuge a compreensão com seus problemas profissionais? E com os problemas domésticos?

29. Você consegue ser a profissional que sonhou ser? Há um padrão (objetividade) de profissionalismo criado/imaginado por você?

30. Você se considera realizada?

31. Quais os principais conflitos que você identifica? Qual seria o principal?

32. Quais as ações tomadas para lidar com os conflitos relacionados?

33. Das atividades familiares diárias que puderam ser relacionadas por você, quais poderiam ser citadas como prioritárias, em detrimento ao trabalho?

34. Das atividades profissionais diárias que puderam ser relacionadas por você, quais poderiam ser citadas como prioritárias, em detrimento à família?

Submetido em: 07.09 .2020

Aceito em: $\quad 30.11 .2020$ 